\title{
Estratégias sociais e educação prisional na Europa: visão de conjunto e reflexões
}

\author{
Hugo Rangel \\ International Watch on Education in Prision, Canadá \\ Université du Québec à Montréal, Departamento de Ciência Política e Educação
}

Tradução: Anne-Marie E. Milon Oliveira

\section{Introdução}

Este artigo originou-se de uma pesquisa sobre o estado da educação prisional na Europa. Apresenta uma reflexão, em vários planos e aspectos, sobre as atividades educacionais desenvolvidas nas prisões, procurando identificar os problemas de ordem organizacional, metodológica e social que as determinam ou que as limitam.

Diversas fontes foram utilizadas na elaboração da pesquisa. Um questionário foi distribuído às autoridades penitenciárias, assim como às organizações não-governamentais e aos que intervêm no meio carcerário dos países estudados. É preciso, todavia, sublinhar que esse instrumento, ainda que muito útil, comportava limites importantes. ${ }^{1}$ Retiramos dele in-

${ }^{1} \mathrm{O}$ questionário revelou-se perfectível e transitório, sendo ultrapassado pela própria natureza da pesquisa. No entanto, o aperfeiçoamento de um instrumento não poderia constituir-se em um dos objetivos da pesquisa. Isso teria significado uma preocupação metodológica (e até acadêmica) que deixaria de lado o próprio objeto da pesquisa. formações disponíveis e completamos com outros recursos. Uma segunda fonte foi constituída pelos documentos oficiais dos países estudados, como, por exemplo, os relatórios nacionais. ${ }^{2}$

Sabíamos, desde o começo, que o caráter fragmentário dos dados e a falta de informação das instituições em questão constituíam um limite para qualquer pesquisa que tratasse do meio carcerário. É preciso, portanto, mencionar o tempo suplementar considerável e o trabalho que foram investidos na pesquisa de informações junto às autoridades e às pessoas capazes de fornecer recursos, a fim de obter a informação necessária e, às vezes, uma opinião sobre essa informação.

\footnotetext{
${ }^{2}$ Sabendo que os documentos oficiais negligenciam freqüen-
} temente as críticas e as disfuncionalidades dos sistemas carcerários, acrescentamos, quando estavam disponíveis, outras informações, a fim de oferecer uma imagem mais equilibrada do assunto. Essas fontes encontram-se relacionadas no final do texto, logo após as referências bibliográficas. As informações obtidas foram completadas e, às vezes, validadas pelos profissionais da área educativa e carcerária, ou ainda pelos próprios documentos. 
No artigo, os resultados da pesquisa são apresentados em quatro blocos. Inicialmente, procuramos, pelos dados colhidos, estabelecer o contexto legal, institucional e social no qual se insere a educação prisional na Europa, para tornar mais claro o entendimento das informações trazidas na segunda seção, que se debruça sobre a organização, pelas administrações penitenciárias, das atividades educacionais desenvolvidas nas prisões, ou seja, sobre o ambiente educativo, as metodologias de ensino e as atividades oferecidas aos detentos, o pessoal envolvido, entre outros tópicos. O terceiro bloco aborda três grupos de detentos que constituem populações específicas e que demandam atenção diferenciada nas atividades educacionais a eles oferecidas. Na quarta seção, tendo em vista que a educação deve ser considerada na sua integralidade, e como um processo que se estende ao longo da vida, são listadas algumas de suas dimensões que estão ou precisariam estar presentes na organização geral das aprendizagens prisionais. Seguem-se a este último bloco as conclusões da pesquisa.

\section{0 contexto legal, institucional e social}

Na Europa, numerosos países aprovaram leis que garantem o direito dos presos à educação. Essas normas legais apresentam geralmente muita semelhança, embora, principalmente nos países do Leste europeu, observe-se uma distância considerável entre o que prescrevem as leis e a vida cotidiana nas prisões. Países como a Bulgária, por exemplo, adotam sistemas rígidos, altamente normativos. Em todos os países, nota-se o crescimento significativo do número de detentos, o que acarreta incontáveis problemas no que tange à aplicação das normas. Além disso, poucos são os recursos destinados a atender às demandas de educação dos presos.

Como mencionou MacDonald (2003), os países da Europa do Leste dão pouquíssima importância às prisões; seus responsáveis políticos concentram esforços em apenas alguns padrões, visando à adesão do seu país à Comunidade Européia, mas as políticas penitenciárias não mudaram na essência e as condi- ções dos detentos continuam precárias. Seria necessário, então, pensar em estratégias globais capazes de traduzir as leis e os regulamentos em práticas e em programas.

Uma visão de conjunto da educação nas prisões européias permite identificar várias problemáticas na realidade muito complexa e diversificada da vida carcerária. Essa complexidade obriga-nos a ser vigilantes, a fim de não cairmos na formulação de generalizações. Nesse sentido, é preciso levar em consideração as diversas dimensões das práticas educativas que estão ou deveriam estar sendo desenvolvidas na prisão, situando suas exigências específicas numa visão mais ampla dos sistemas de justiça e de administração dos programas educativos.

A complexidade do meio carcerário, sua natureza multidimensional, a importância dos contextos socioeconômicos e o espírito crítico com o qual devem ser abordadas as práticas educativas permitem-nos afirmar que o discurso das best practices, muito em moda nos meios penitenciários, é incompatível com a realidade da educação prisional. Esse discurso comporta riscos, pois veicula uma ingenuidade acrítica que negligencia os contextos e os problemas sistêmicos. Um olhar comparativo sobre a educação prisional na Europa obriga-nos a afirmar que não existem fórmulas ou modelos a serem seguidos. Daí decorre a importância de valorizar as práticas educativas numa perspectiva geral.

Uma das constatações da pesquisa realizada é que boa parte do "sucesso" de certos programas educativos depende da implementação simultânea de diferentes estratégias, tanto no plano da administração judiciária como no acompanhamento dos detentos após sua liberação. O "sucesso" dos programas educativos adotados nas prisões pelos países escandinavos pode, a nosso ver, ser explicado a partir dessa leitura e, é claro, de programas sociais que seguem uma estratégia social e comunitária fora da prisão.

Organizando-se serviços e ficando-se atento à população de risco, tem-se a melhora das condições de vida e evita-se a repetição do círculo (infernal) prisão-marginalidade-recidiva. Um modo de melho- 
rar a educação nas prisões é trabalhar também fora dos muros, no âmbito comunitário. Saliento que as administrações dos países escandinavos têm como preocupação a formação dos detentos para a autonomia, inclusive nos atos da vida cotidiana. Essa dimensão educativa, por dirigir-se a pessoas freqüentemente dependentes, deveria ser generalizada e fundamentar os programas educativos. Se o objetivo é que os detentos possam superar sua condição, não se deve habituá-los à vida carcerária (a serviços de cozinha e de limpeza, por exemplo).

Poder apresentar uma gestão eficaz das prisões e dedicar atenção aos detentos depende também do nível de estabilidade da população carcerária. A Europa beneficiou-se, nos últimos tempos, de uma estabilidade em suas taxas de encarceramento. Mas, como já foi mencionado, essa situação está mudando: a Alemanha, a Inglaterra, os Países Baixos e, particularmente, a Espanha tiveram taxas de crescimento importantes das suas populações carcerárias ao longo destes últimos anos. ${ }^{3}$ A superpopulação, como se sabe, provoca numerosos problemas e acentua os que já existem. Freqüentemente, e cada vez mais se acentuando, as políticas de encarceramento estão ligadas a uma visão punitiva e securitária, produzindo mais problemas do que soluções. Nessa situação, a educação fica em segundo plano, sendo muitas vezes cortada ou reduzida nas prisões superpovoadas.

Salvo exceções, constata-se, mesmo nos países da Europa Ocidental, que os recursos destinados às administrações penitenciárias são insuficientes para permitir o desenvolvimento de programas educativos, embora estes sejam considerados necessários. Isso reflete a pouca importância das prisões nas preocupações políticas e nas decisões econômicas. A necessidade de uma perspectiva global de educação integrada não atrai o interesse dos detentores do poder de decisão e tampouco da opinião pública.

3 A Espanha duplicou sua população carcerária desde 1990, e atualmente a taxa de detentos por 100 mil habitantes é de 146, a mais alta da Europa.
Quase todos os países que têm leis ou regulamentos prevendo e garantindo o direito à educação na prisão aceitam geralmente que esses direitos sejam implementados por organizações não-governamentais. Todavia, verifica-se com excessiva frequiência que tais iniciativas se limitam a uma visão da educação como intervenção terapêutica ou de reabilitação ou, pior ainda, a um tratamento especial para os detentos. É muito raro constatar que as autoridades nacionais consideram a educação prisional um direito universal, embora essa opção lhes pudesse conferir uma legitimidade internacional e reforçar a coesão nacional.

Essa ausência de estratégias nacionais no que se refere à educação prisional foi identificada com freqüência na pesquisa. Conclusões similares foram enunciadas por comissões parlamentares, tanto na Inglaterra como na França, salientando a ausência de coordenação das políticas e das instituições governamentais no desenvolvimento de estratégias para a educação prisional e assinalando a impossibilidade, muitas vezes, de identificar responsáveis públicos. Volta e meia, reina certa confusão quando se trata de designar o organismo responsável pela educação prisional: o ministério da justiça ou o da educação, ou organismos de formação para ao trabalho etc.

Essa confusão é produto ou expressão de uma falta de vontade política? Os centros penitenciários ficam enredados nessa indefinição institucional. Eles administram as urgências com um financiamento insuficiente e, na falta de interlocutor público, vêem-se empurrados para a improvisação.

\section{A educação e a administração penitenciária}

As questões de segurança têm um impacto sobre a organização e sobre o desenvolvimento dos programas educacionais que se destinam aos detentos. Em razão disso, não é de surpreender que as restrições e as regras mais severas de alguns países reduzam os espaços e as possibilidades de aprendizagem, enquanto países com restrições menos severas, como os da Escandinávia, oferecem mais flexibilidade para a organização das atividades e dos programas educativos. 
Outro dado importante a ser considerado é a atuação dos agentes penitenciários, que, segundo vários países assinalam, recebem uma formação especializada; alguns a adquirem no interior mesmo da instituição penitenciária. Apesar disso, os profissionais e as outras pessoas que intervêm na prisão insistem no fato de que esses agentes são freqüentemente pouco qualificados, que pouco colaboram, dificultam, ou até, às vezes, sabotam as atividades educativas.

Assim, constata-se uma carência no que se refere à sensibilização do pessoal para as atividades educativas e o seu lugar na prisão. O mesmo dá-se quanto ao percurso individual de cada detento. $\mathrm{O}$ interesse suscitado pelas questões de segurança justifica-se, mas não deve servir de motivo para a imobilidade ou a inatividade dos presos.

Conforme relatam vários organismos e várias pessoas que intervêm nas prisões, essa falta de sensibilidade para com o que está em jogo nas questões educativas está também presente em algumas autoridades penitenciárias.

É importante assinalar que vários países afirmaram que a opinião dos detentos era levada em consideração na programação das atividades, apesar de, por falta de recursos, só uma parte mínima dessas sugestões ter sido concretizada por meio de cursos. Nesse contexto, compreende-se a participação nessas atividades apenas de uma minoria, estimada em $30 \%$ dos presos (18\% na França, $11 \%$ na Finlândia; na Bulgária, de um total de 11.000 presos, apenas 650, isto é, menos de $6 \%$, faziam algum curso). Portanto, a oferta de cursos e de programas educativos deve, imperativamente, ser aumentada.

Como motivar os detentos? Essa é a pergunta que se coloca para as administrações das prisões, que se vêem, volta e meia, confrontadas com a falta de interesse dos detentos em participar das atividades educativas. A motivação por meio de recompensas (por exemplo, a redução da pena, a liberdade condicional e a remuneração simbólica) é, sem dúvida, um caminho.

Constata-se que a redução de pena para os detentos que participam das atividades educativas é percebida por eles como muito positiva. Além de motivá-los, ela é um meio para que superem sua situação e, às vezes, para evitar que caiam em recidivas. A legislação de vários países concede uma redução de pena para os prisioneiros que trabalham, mas a sua participação em atividades educativas é ainda pouco recompensada dessa forma.

Existem países que concedem a liberdade condicional após o exame de um dossiê pessoal, que menciona e valoriza o trabalho e a participação do detento em atividades de estudo. Por diversas razões, essa medida não pode ser generalizada, mas poderia ser concedida com maior freqüência se houvesse uma coordenação das libertações condicionais, acompanhada de uma redução das penas, e se fosse estabelecido um programa de acompanhamento educacional após a liberação.

Alguns países da Europa Ocidental oferecem outra forma de recompensa aos presos que participam dos programas educativos: uma remuneração simbólica. Esse dispositivo pode certamente contribuir para atenuar ou até contrabalançar a concorrência entre o trabalho e os estudos na prisão. Assim, as autoridades presidiárias devem prioritariamente levar em consideração os interesses simultâneos dos detentos (necessidade de renda para alimentar-se, e de educação com vista à saída) e, ao mesmo tempo, estar a par da demanda imediata do mercado de emprego fora da prisão. Apesar disso, os recursos humanos e financeiros continuam sendo um obstáculo à resposta a ser dada aos pedidos de formação.

\section{Um perfil das atividades educacionais}

A organização da educação nas prisões não deixa de guardar relações com a que existe fora delas, principalmente no que se refere à atribuição de certificados e à sanção dos estudos pelas autoridades acadêmicas. Isso se verifica mesmo quando a especificidade do setor faz com que os próprios sistemas judiciários determinem o conteúdo dos programas e as abordagens educativas a serem implementadas na prisão. 
O modelo de atividades educacionais que predomina nas prisões é aquele que liga o trabalho em oficinas às empresas. Nesse contexto, a oferta de cursos limita-se às oficinas e às formações disponíveis. $\mathrm{O}$ trabalho para oficinas terceirizadas é freqüentemente percebido ou apresentado como "a verdadeira formação", embora esse modelo comporte limites para a formação e a reinserção do indivíduo. Se a formação técnica ou profissional é primordial para desenvolver as habilidades dos detentos, seus limites e suas contradições devem ser assinalados e até denunciados.

Além disso, apesar de existir, às vezes, uma oferta generosa de programas, os cursos realmente disponíveis são frequientemente aqueles que se referem ao ensino fundamental ou ao ensino médio: os da primeira à quarta série são amiúde estandardizados e pouco adaptados, do ponto de vista metodológico, à população carcerária.

Em vários países são utilizados para alguns cursos materiais pedagógicos destinados a crianças, embora se saiba que, por serem inapropriados para as populações às quais se dirigem, se revelarão ineficazes, ou até contraproducentes. Enfim, a maior parte do material é concebida para uma pedagogia de grupo, quando, no caso das prisões, assim como para toda população desfavorecida -, a atenção individual seja um elemento importante do trabalho pedagógico, como, por exemplo, nos cursos de alfabetização, de expressão etc.

Ainda que numerosos países mencionem a existência de bibliotecas acessíveis aos detentos, é necessário assinalar que o material disponível é freqüentemente vetusto e limitado. Em contrapartida, as restrições quanto à mobilidade no interior das prisões e uma concepção ainda tradicional de cultura impedem uma utilização maximizada dos lugares. Espaços institucionais, tais como bibliotecas, são subutilizados, desprovidos de qualquer projeto dinâmico, quando poderiam e deveriam propor atividades e serviços variados ao conjunto da comunidade que vive dentro e em volta da prisão. Assim, a biblioteca poderia tornarse um centro de atividades culturais variadas, beneficiando os detentos. Tornar-se-ia um espaço específico e um ambiente educativo para todos. Na Noruega, por exemplo, a biblioteca de uma prisão feminina é utilizada como centro de reuniões e de trocas para as mulheres que se apropriaram desse lugar. ${ }^{4}$

Os detentos são preparados para prestar exames estandardizados, formatados, universais. Como consequiência, os docentes têm pouca margem de manobra e devem seguir os currículos das instituições ou dos ministérios da educação. $\mathrm{O}$ fato de nem os conteúdos nem os métodos serem adaptados para essa população constitui um grande obstáculo para a aprendizagem. É preciso lembrar que a maioria dos detentos viveu fracassos no sistema escolar e que as mesmas metodologias, transpostas para a prisão, estão fadadas a produzir o mesmo resultado.

\section{O dossiê pedagógico e a avaliação}

Com muita freqüência, os cursos ministrados aos detentos são iniciativas pouco estruturadas e sistemáticas. A ausência de avaliação desses programas é evidente. As autoridades presidiárias não dispõem de informação sobre o acompanhamento dos detentos, a não ser em caso de reincidência. Nessa situação, torna-se difícil estabelecer um balanço dos processos de aprendizagem nas prisões. Fica patente a necessidade de instaurar-se toda uma cultura da avaliação. A constituição de um dossiê pedagógico pode facilitar um acompanhamento acadêmico no interior das prisões, em caso de transferência para outras prisões e na hora da liberação do indivíduo. Sem estabelecer normas abusivas e sem que sejam utilizados para fins punitivos, sua generalização pode ser muito útil para um acompanhamento sociocultural e profissional de cada preso.

Uma comissão parlamentar do Reino Unido confirmou essa necessidade de um sistema individual de aprendizagem estruturado em função da sentença a

\footnotetext{
${ }^{4}$ Observação realizada durante a visita organizada pela
} International Adult Learners Weck (IALW), em Oslo, em outubro de 2005 . 
ser cumprida pelo detento (System of Individual Learning Plans Linked to Sentence Plans), sistematizando e registrando suas aquisições. Esse dossiê pedagógico pode ser uma ferramenta valiosa, desde que esteja a serviço do detento, não devendo penalizar aqueles que têm competências intelectuais reduzidas.

Existe o risco de um detento apresentar um dossiê pedagógico fraco (em virtude das suas carências escolares iniciais), que influa negativamente sobre uma decisão de liberação condicional, mesmo que o detento tenha empenhado os esforços dele requisitados. É essencial, portanto, proceder a uma avaliação individual que leve em conta seus progressos escolares, mesmo que ainda muito fracos. Uma redução de pena ou uma liberação condicional não podem ser adiadas por uma avaliação estritamente "escolar" das atividades de formação cursadas pelo detento. Ou seja, um dossiê pedagógico não é um boletim escolar.

\section{A atribuição de certificados}

Como ocorre em outras burocracias, as administrações penitenciárias são regularmente convidadas a entregar relatórios e balanços sobre sua "produtividade". Assim, dados quantitativos começam a estar disponíveis sobre as iniciativas de base: estatísticas, número de cursos ministrados, número de detentos inscritos, número de diplomas expedidos.

Algumas administrações atribuem diplomas para cursos de curta duração; esses diplomas têm freqüentemente um valor simbólico, muito importante para os detentos que os recebem, mas de pouco valor legal, pois dão poucas informações sobre as aprendizagens efetivas. Além disso, observou-se que o grande número de diplomas atribuídos é uma forma de pressão sobre as autoridades: ao salientarem a amplitude das realizações, fortalecem e legitimam os pedidos de meios financeiros suplementares.

\section{Os atores voluntários}

Ligada à escassez de recursos financeiros, materiais e humanos, observa-se uma participação cres- cente de grupos voluntários no interior das prisões. Isso seria inegavelmente um fator positivo se as autoridades públicas não aproveitassem para se livrar, com tanta freqüência, de suas responsabilidades (serviços, educação), entregando as tarefas que lhes cabem para as organizações não-governamentais, organismos religiosos beneficentes. Pessoas que intervêm nas prisões assinalaram a falta de formação e de supervisão dos voluntários que participam das atividades, particularmente das atividades educativas. É preciso então pensar numa supervisão e numa formação adequada dos voluntários envolvidos com os programas educativos, os quais devem estar bem estruturados.

Em certos países, as organizações não-governamentais coordenam seus esforços; que se apropriaram desse lugar ${ }^{5}$ em outros, elas ficam isoladas e pouco estruturadas, o que torna mais imperativa ainda a publicização de políticas educativas fortes por parte dos governos nacionais. Mas, acima de tudo, a participação dessas organizações não pode fazer esquecer que o Estado continua responsável pelas prisões, pelos seus programas educativos e pelas políticas de reinserção social. A atuação delas, cujos interesses e estruturas são diferentes do poder público, deve ser complementar, apoiando a ação do Estado e sendo coerente com ela. Assim, a coesão da oferta educativa será fruto da formulação e da implementação de uma política governamental forte.

\section{Após a liberação}

Após a liberação, a implementação de programas socioeducativos de acompanhamento reduz os riscos de recidiva, mas eles são ainda muito escassos. Muitas vezes discriminados e estigmatizados por causa do seu passado, os egressos das prisões deveriam poder beneficiar-se de projetos educativos específi-

${ }^{5}$ Tal é o caso na Bélgica, onde a Federação das Associações para a Educação e a Formação nas Prisões (FAFEP) coordena o trabalho associativo do governo com as organizações não-governamentais. 
cos, capazes de assegurar continuidade nos estudos e no trabalho. As necessidades constatadas na prisão são ainda mais gritantes fora dela, após a liberação, em virtude da ausência de iniciativas e mecanismos que auxiliem os egressos a abrir caminhos. Assim, as instituições carcerárias devem preocupar-se (como ocorre nos países escandinavos, conforme já mencionado) com a preparação dos detentos para que vivam de maneira autônoma, inserindo-se, após cumprirem suas penas, numa perspectiva de educação ao longo da vida.

\section{Populações específicas}

\section{As mulheres}

As mulheres detentas são nitidamente menos numerosas que os homens. Mas o que poderia representar uma vantagem em termos de gestão torna-se uma desvantagem, pois as administrações não costumam fornecer-lhes cursos específicos em razão do número reduzido de mulheres "interessadas" em freqüentar determinado curso. Note-se que, recentemente, em vários países, o número de detentas vem aumentando.

Na pesquisa realizada, queríamos saber se os programas educativos ministrados às mulheres limitavam-se aos cursos tradicionais. Infelizmente, em vários países, eles sequer existem. Por falta de recursos e de iniciativas, a formação das mulheres está à deriva, ou então se reduz a um ensino muito tradicional. As condições de superpopulação dos presídios constituem ainda, mesmo nesses grupos menores, um entrave para a organização da educação.

As mulheres pertencentes a minorias étnicas são geralmente ainda mais necessitadas e isoladas, e têm, freqüentemente, mais problemas de saúde, como será visto adiante.

\section{Os jovens}

O número de jovens está em alta nas prisões européias: eles constituem $46 \%$ da população carcerária na França e 45\% na Bulgária. Os programas educativos destinados a jovens detentos devem propor alternativas realistas de vida ante as difíceis condições sociais que freqüentemente foram as suas, antes do encarceramento, principalmente porque esse grupo apresenta graves problemas de aprendizagem. Aprender a aprender constitui certamente um objetivo prioritário.

Em vários países, como na Inglaterra, foram criadas escolas para jovens presos, mas essas iniciativas são ainda por demais escassas. Programas de educação não-formal devem ser propostos, a fim de que a expressão das emoções e das frustrações, que é uma necessidade para toda vivência coletiva, possa ser adquirida.

\section{As minorias culturais}

Constata-se um número crescente de pessoas pertencentes a minorias culturais nas prisões européias. A super-representação dessas populações em comparação com sua presença nas populações nacionais constitui, por si só, uma expressão da condição social marginal desses grupos. A presença das minorias culturais representa um fenômeno marcante, identificável em vários aspectos da vida carcerária, entre os quais a saúde e as atividades educativas. $\mathrm{O}$ fato de os migrantes não dominarem a língua oficial falada na prisão condena-os a um isolamento suplementar que não favorece a sua reinserção e incentiva a formação de enclaves comunitários. Deve-se assinalar que vários países criaram programas especiais para esses detentos. Apesar disso, de uma forma geral, existe um claro déficit de programas educativos e de ajuda para essa população.

A participação das minorias culturais em atividades é ambígua: às vezes, esses detentos participam das atividades educativas ou de outros programas por razões de segurança e de conformismo. Seria interessante valer-se dessa realidade para tirá-los dessa participação passiva e levá-los a um processo de valorização individual durante a detenção, na perspectiva de preparar e favorecer sua saída. 
A diversidade cultural constatada nas prisões manifesta-se também pela expressão religiosa. A indagação que permanece é: de que forma as atividades educativas poderiam levar em consideração essas diferenças religiosas a fim de favorecer o espírito crítico, permitir a compreensão das atitudes e criar um ambiente de tolerância, propício à vida coletiva?

\section{D imensões da educação}

Partindo-se do entendimento de que a educação deve ser considerada na sua integralidade, e como um processo que se estende ao longo da vida, são listadas a seguir algumas de suas dimensões que estão ou precisariam estar presentes na organização geral das aprendizagens prisionais.

\section{A educação para a saúde}

A oferta de programas de educação para a saúde é imperativa, ainda mais se levando em conta que o número e a gravidade das doenças ocorrem de forma proporcionalmente mais importante na prisão do que fora dela. As infecções, como o HIV e as hepatites, são particularmente numerosas. A taxa de suicídios é também proporcionalmente muito mais elevada que no exterior.

Na Europa Ocidental, o HIV está particularmente presente nas prisões de Portugal (20\%) e da Espanha $(16 \%)$. A partir de um estudo realizado em dez países da Europa do Leste, Macdonald (2005) afirma que o consumo de drogas está em crescimento nesses países, e que às vezes drogas são injetadas nas próprias prisões; há também uma incidência crescente de casos de hepatite entre os presos.

Sabe-se que os programas de distribuição de seringas para as pessoas dependentes de drogas podem reduzir as infecções. Mas isso pressupõe que as autoridades admitam a existência e a circulação de drogas dentro dos estabelecimentos penitenciários, e que essa distribuição seja acompanhada de informações psicomédicossociais. Chega-se aqui a uma das maiores dificuldades de implementação de tais programas.
Esses problemas conjugam-se com a superpopulação e com a grande necessidade de renovação da infra-estrutura das prisões. A educação para a saúde é, assim, uma necessidade absoluta. O tratamento das doenças deve imperativamente ser acompanhado de programas educativos de prevenção, sensibilização e formação dos detentos. A prevenção das doenças por meio de programas de educação para a saúde constitui também uma forma de economizar fundos e recursos, mas esse não é, evidentemente, o argumento essencial.

A distribuição de preservativos deve ser acompanhada de programas educativos (sexualidade, respeito pelo outro, higiene, contracepção etc.). Como menciona Macdonald (2005), é preciso também relembrar que a situação sanitária das mulheres é particularmente preocupante na Europa do Leste. O estado de saúde dos detentos imigrantes e das minorias étnico-culturais (ciganos, por exemplo) é freqüentemente precário, e não é raro que o exame médico feito na prisão seja o primeiro de suas vidas.

A tuberculose permanece um problema grave. É preciso desenvolver estratégias de prevenção e de sensibilização, assim como apoiar a implementação de amplos programas de higiene. É preciso também que os prédios penitenciários passem por reparos, o que raramente acontece. $\mathrm{O}$ estado sanitário de certas prisões provoca o aparecimento ou aumenta a incidência de certas doenças (sem falar na influência da "arquitetura" das prisões sobre a saúde psíquica dos detentos).

\section{As tecnologias da informação e comunicação}

A aprendizagem da informática foi mencionada em diversos casos como uma das atividades organizadas na prisão. Parece de fato difícil ignorar as tecnologias da informação, inclusive no meio carcerário. Vários países mencionam a acessibilidade aos computadores (reduzida por razões evidentes de segurança). Aprender informática é uma necessidade, mas utilizá-la como metodologia é questionável. Efetivamente, é extremamente importante colocar a questão 
da informática como instrumento de aprendizagem para os indivíduos privados de liberdade. Estudos recentes salientam a necessidade de oferecer tutorias adequadas, que venham obrigatoriamente em complemento dos programas educativos online ou por softwares. Ou seja, o ensino tem uma dimensão comunitária. Como dizia Paulo Freire, a educação é dialógica, exige a comunicação.

As administrações penitenciárias apresentam (como o fazem as universidades) a incorporação das tecnologias da informação como uma imagem da modernidade. No plano simbólico, a sua apropriação é útil para os detentos, mas, em linhas gerais, não substitui o acompanhamento.

Apple (2004) salienta que, para seguir essa idéia de modernidade, as instituições educativas gastam excessivamente em computadores e em equipamentos, mas que isso serve cada vez menos para melhorar a educação e a supervisão. É preciso, então, superar essa imagem de modernidade e compreender o papel das tecnologias da informação (certamente indispensáveis na vida cotidiana) em um meio marcado pelas carências financeiras e educativas.

Em compensação, a informática e os meios tecnológicos de informação e comunicação não devem, em caso algum, substituir a equipe pedagógica. $\mathrm{O}$ computador não substitui o docente. Essa restrição não significa que não se deva encorajar o estudo da informática, ferramenta essencial da formação profissional. Para além do símbolo da modernidade, há o domínio de um instrumento; isso é também seguir uma direção pedagógica.

\section{As línguas utilizadas no ensino}

A presença, por vezes significativa, de imigrantes e de pessoas oriundas de grupos minoritários constitui um questionamento para os processos de alfabetização. A aprendizagem de uma segunda língua não pode ser confundida com a alfabetização na língua materna. Com frequiência, a utilização da língua materna ajuda na aprendizagem de uma segunda língua, como o provam numerosos estudos realizados nos Estados Uni- dos com populações hispanófonas estudando inglês. Alguns desses estudos explicam o esquecimento da língua materna, às vezes por razões financeiras.

Pesquisas recentes mostram, todavia, que o conhecimento de sua própria língua, longe de retardar os progressos do aluno, lhe permite adquirir mais rapidamente as mesmas aptidões numa outra língua. Em um plano estritamente econômico, esse método também se justifica. No âmbito dessa comunidade imposta, que é a prisão, os detentos poderiam assim desenvolver novas oportunidades de comunicação, como, por exemplo, a edição de jornais.

\section{A alfabetização}

Programas de alfabetização são organizados em numerosas prisões e assumem às vezes um caráter obrigatório, sobretudo para os jovens. Mais do que qualquer outro tipo de ensino, a alfabetização necessita de uma abordagem dinâmica, crítica e participativa - tal como propôs Paulo Freire. Apesar disso, constata-se que as aulas de alfabetização são freqüentemente organizadas de modo convencional, com conteúdos rígidos e pouco propícios a gerar interesse nos alunos.

Durante um seminário sobre educação não-formal organizado pela Organização das Nações Unidas para a Educação, a Ciência e a Cultura (UNESCO), foi colocada a questão da natureza da alfabetização: será ela formal ou não? Essa distinção não é unicamente semântica, mas também metodológica e conceptual: a alfabetização escolarizada, tal como é abordada em vários países europeus, pode ser um obstáculo para o desenvolvimento de uma educação dinâmica e participativa. Acompanhar a evolução de um indivíduo requer uma metodologia mais flexível. E deve-se prever necessariamente um apoio que facilite a transição para o nível primário.

\section{O trabalho e a formação}

Como já foi mencionado, observa-se que os programas educativos desenvolvidos nas prisões enfati- 
zam por demais o desenvolvimento de competências para o trabalho. A princípio, a escolha desse caminho é perfeitamente justificável, a fim de possibilitar aos presos sua reinserção social. Mas a realidade é bem diferente, pois a formação em oficinas, que são, na realidade, muitas vezes, fábricas terceirizadas, demonstrou poucos resultados convincentes no que se refere à formação dos detentos e à sua absorção pelo mundo do trabalho.

Experiências feitas na França e no Reino Unido mostram que essas oficinas se vêem confrontadas com os dilemas e as exigências que opõem a produção competitiva à organização de uma formação adequada.

O modelo de formação pelo trabalho na prisão está em crise, tanto no plano europeu como no plano internacional; países da América Latina, da Ásia e da África estão desenvolvendo programas educativos centrados principalmente na formação para o trabalho, e isso mediante oficinas de produção. Constatou-se que esse modelo não se adapta às reais necessidades educativas dos detentos, pois o objetivo principal dessas oficinas é a produção, e sua exigência imediata, a rentabilidade. A preocupação com uma formação mais adequada dos detentos torna-se, então, secundária.

A insuficiência dos recursos públicos destinados aos sistemas carcerários obriga as administrações a realizar parcerias com a iniciativa privada. Nesse contexto, podemos compreender melhor a participação crescente do setor privado nas prisões, e o debate em torno dessa participação comporta certamente numerosos elementos. No entanto, não é certo que essas parcerias tornem as condições menos desfavoráveis para as prisões, nem, particularmente, para os detentos. Quando a terceirização impõe seus interesses, os dos detentos e os das instituições carcerárias caem para o segundo plano.

\section{O direito de voto e a cidadania}

Na maioria dos países europeus, os detentos têm direito de votar. Dezoito países da Europa, dentre eles a Espanha, a Irlanda e os Países Baixos, não impõem qualquer restrição a esse direito; oito países o suspendem para os detentos condenados a algumas sentenças bem precisas. Apenas uma minoria de países (oito), entre os quais a Inglaterra, a Bulgária, a Romênia e a Rússia, suprimem automaticamente o direito de voto dos presos a partir de sua condenação.

Várias organizações, como a Penal Reform, propõem que os detentos sejam encorajados a votar para que adquiram, progressivamente, o conhecimento e a consciência da sua responsabilidade cidadã. $\mathrm{O}$ direito de votar (e a pedagogia que o acompanha) pode provocar neles um sentimento de interesse para assuntos que ultrapassem sua própria sobrevivência na prisão e, eventualmente, motivá-los a participar de atividades na prisão e, depois, na sociedade.

Outro argumento é que o voto de numerosos detentos favorecerá um crescimento de interesse, por parte dos políticos, para com a organização geral das prisões. Como foi visto, as prisões não constituem, ainda, uma prioridade dos governos, tampouco da opinião pública. Integrar os detentos nos processos de votação (e de participação social) pode, eventualmente, "tirar as prisões" do isolamento e dessa falta de interesse por parte do poder público e da sociedade em geral.

\section{A educação não-formal}

Tendo em vista os limites comprovados do modelo de formação baseado em oficinas, outras alternativas educativas têm de ser consideradas. A educação não-formal oferece um leque de possibilidades de formação, de sensibilização e de expressão para os detentos, que devem ser analisadas com interesse. Embora vários países venham implementando a educação não-formal (por exemplo, Bélgica e Espanha), não se assiste ainda à criação de redes de troca. Mais ainda, contata-se uma falta de valorização desse tipo de educação, persistindo uma visão segundo a qual as atividades educativas não-formais são, essencialmente, "ocupacionais".

$\mathrm{Na}$ Europa, os numerosos projetos de educação não-formal são geralmente de uma grande riqueza e 
de um valor educativo comprovado. Esses programas constituem meios de expressão e são portadores de uma visão mais aberta, que é necessária à prisão e aos detentos. Quando se sabe que a maioria dos detentos teve dificuldades com o ensino formal (na Inglaterra, $60 \%$ têm pouca habilidade com a leitura e a escrita), a educação não-formal aparece como uma possibilidade de aprender de outra forma.

\section{A educação e as necessidades terapêuticas}

O número crescente de detentos que enfrentam problemas com drogas provocou a reação das autoridades, e cada vez mais governos têm implementado (ou deixado implementar) programas visando ao tratamento desses dependentes. Certos programas desenvolveram uma abordagem sistemática. Os chamados programas de desintoxicação são, de per si, uma forma de lutar contra o tráfico, fonte de violência e de corrupção no interior das prisões.

Os programas que se referem às drogas pesadas são, evidentemente, difíceis de ser desenvolvidos, por demandarem um acompanhamento constante. Além disso, a presença importante de drogas nas prisões (o que incomoda as autoridades) constitui uma dificuldade suplementar.

O alcoolismo é outra realidade muito presente, e também muito difícil de ser tratada num lugar de desesperança. Ainda assim, propor pistas para enfrentar essa doença favorecerá uma diminuição da reincidência.

É, portanto, necessário identificar as necessidades terapêuticas ligadas aos comportamentos delituosos. Uma avaliação de cada detento deve ser feita, em uma perspectiva terapêutica, mas também como forma de fornecer-lhe, progressivamente, as chaves da compreensão da sua dependência. O objetivo não é, evidentemente, "tratar os doentes" ou medicalizar a delinqüência. Mas existe um campo de pesquisas e de experiências para uma abordagem que não seja incompatível com a eficácia terapêutica.

No que se refere aos delitos sexuais, em alta nas prisões de vários países, programas e tratamentos terapêuticos são disponibilizados. Eles deveriam integrar uma educação para a sexualidade e para o respeito.

Quanto aos motoristas alcoolizados, a educação pode fazer parte dos programas de tratamento terapêuticos, como é o caso de projetos desenvolvidos na Noruega (Anger, Stress Management, Drunk Drivers, Sexual Offences), que procuram ir além da punição. Os detentos acusados de infrações ligadas a condutas agressivas são tratados de forma indireta, mediante ateliês de gestão da cólera ou de autoconhecimento, que visam fazer com que cheguem a compreender as razões que os levam a cometer diversas infrações.

Projetos artísticos, como o teatro, podem contribuir para canalizar a agressividade e ajudar a expressála de outra forma. Segundo relataram pessoas que intervêm nas prisões, cursos de ioga que são realizados em várias delas ajudaram a neutralizar detentos anteriormente violentos.

A educação ao longo da vida, entendida como um processo que engaja o educando, constitui um elemento fundamental do encaminhamento terapêutico.

Para superar a visão terapêutica, a educação nãoformal permite uma objetivação na tentativa de resolução de problemas concretos (tratamento da violência, perturbações do comportamento etc.). Ela é parte integrante da educação nas prisões e oferece um espaço de encontro às diversas personalidades reunidas por acaso nesse lugar fechado.

\section{A educação para a tolerância}

Assiste-se atualmente a um aumento do racismo e da xenofobia em vários países da Europa e no interior das prisões (entre os detentos, assim como entre eles e os carcereiros). Um número cada vez maior de delitos tem uma origem racista ou xenófoba. Programas como o Xenos, na Alemanha, tentam prevenir esse tipo de crime, sensibilizando os detentos e os que intervêm nas prisões, preparando-os para enfrentar, compreender e aceitar as diferenças.

É preciso também sensibilizar e formar os agentes penitenciários, que têm de conviver com detentos 
imigrantes, pertencentes a diversas religiões. Uma formação para a diversidade cultural e religiosa deve ter seu lugar no currículo desses agentes, facilitando, assim, a coabitação no interior da prisão.

\section{Conclusões}

Aprender a viver de forma independente, porém em uma comunidade

Um bom número de programas de educação prisional adota atitudes paternalistas, moralistas ou abordagens terapêuticas. Não há dúvida de que certos detentos necessitam de serviços de saúde mental, serem reconfortados ou receberem um apoio individual personalizado. Além disso, boa parte dos detentos marginalizados, às vezes sem teto, sem laços familiares, busca referências, apoio para viver de uma forma autônoma, fazer parte de uma comunidade. Nesse sentido, é fundamental diversificar as pistas de reflexão para responder a uma demanda tão difusa e não-verbalizada.

O processo educativo, na sua integralidade, deve ser implementado na prisão. Não se trata apenas de organizar sessões de formação (em contraparida, muito necessárias), senão de aderir - em toda medida possível - à realidade cotidiana, para fazer dela um terreno de aprendizagens: relacional, social, acadêmica, não-formal, econômica. Ainda se está longe disso na organização geral das prisões.

É preciso propor, de novo e sem parar, o ensino de base que é perdido freqüentemente durante a estadia na prisão. É preciso encorajar a divulgação e a pesquisa de informações sobre a realidade econômica, o consumo, os recursos comunitários, os cuidados de saúde, a procura de empregos, o funcionamento das instituições, o Estado, os direitos humanos e os valores universais.

Para poder encarar os múltiplos desafios da educação prisional, é necessário prever uma grande reorganização. Esse desafio requer, também e principalmente, uma visão e uma abordagem que vê na educação um processo ao longo da vida. Nesse sentido, a improvisação e a inadequação constatadas nos programas destinados a adultos são reveladoras de uma falta de visão política em educação. A educação de jovens e adultos não é uma educação para crianças grandes; a formação não é a educação ao longo da vida. O fato de o ensino resumir-se, com tanta freqüência, à educação profissional é revelador dessa falta de horizontes.

A educação ao longo da vida almeja um objetivo mais amplo, que vai além das aptidões e da distribuição de informações, como ocorre nas salas de aula. A educação refere-se a atitudes, que não devem ser reproduzidas sem que se entenda seu sentido, mas que devem ser compreendidas.

Duguid (2000) afirma, com razão, que a educação, se não provocar uma mudança de atitudes nos detentos, só faz criar criminosos qualificados. É preciso relembrar aqui o perfil majoritário dos detentos: a maioria cometeu crimes ligados às drogas, roubos $\mathrm{e}$ atos contra a propriedade (os assassinos são minoria). A mudança bem interiorizada de atitudes constitui, com certeza, um objetivo da educação, mas ela deve ser acompanhada de alternativas. $O$ contexto vai determinar as atitudes que se quer mudar: a situação de uma mãe solteira que cometeu um furto leve ou transportou droga para alimentar seus filhos é muito diferente da situação de um pedófilo.

O essencial da educação ao longo da vida é que ela seja reconhecida como um direito universal, inerente à formação cidadã. $\mathrm{E}$ isso é uma verdade, tanto no interior da prisão como fora dela.

\section{Referências bibliográficas}

APPLE, Michael W. Are we wasting money on computers in schools? Education Policy, n. 18, p. 513-522, 2004.

DUGUID, Stephen. Can prisons work? The prisoner as object and subject in modern corrections. Toronto: University of Toronto Press, 2000.

MACDONALD, Morag. A study of the health care provision, existing drug services and strategies operating in prisons in ten countries from Central and Eastern Europe. Helsinki: Heuni, 2005. A comparative report of health care provision in prisons in Poland, Hungary and the Czech Republic. Finland: Heuni, 2003. 


\section{O utras fontes consultadas}

BARRED from voting. Prison reform trust. London: PRT, 2001. BASIC facts. Information and statistics about the Swedish prison and probation service. Swedish Prison and Probation Administration, 2006.

CZECH prisons. Prague: Prison Service of the Czech Republic, 2006.

GALERA, Laura. La educación en las prisiones españolas. Barcelona: Universidad de Barcelona, 2004.

ILOVICSNÉ TÖRÖK, Ágota. Hungary prison report. Budapest: Hungary Ministry of Justice, 2005.

INFORME general. Dirección General de Instituciones Penitenciarias, Ministerio del Interior de España, 2003.

IRISH prison annual report. Dublin: Irish Prison Service, 2004.

LOI de principes concernant l'administration des établissements pénitentiaires. Bruxelles: Gouvernement de la Belgique, 2005.

NORDIC prison education, a lifelong learning perspective. Copenhagen: Nordic Council of Ministers/TemaNord, 2005.

PRACTICE and collaboration for education in European prisons.

The case study of Greece. Thessaloniki, Greece: ARSIS Association for the Social Support of Youth Reality, 2004.

PRISON treatment act. Norrköping: Swedish Prison and Probation Administration, National Labour Market Board, 1999.

RÉPONSE du gouvernement italien au rapport du Comité Européen pour la Prévention de la Torture et des Peines ou Traitements Inhumains ou Dégradants (CPT). Strasbourg, 2004. REPORT to the Lithuanian government on the visit to Lithuania carried out by the European Committee for the Prevention of Torture and Inhuman or Degrading Treatment or Punishment (CPT). Strasbourg, 2004.

REPORT to the Polish government on the visit to Poland. European Committee for the Prevention of Torture and Inhuman or Degrading Treatment or Punishment (CPT). Strasbourg, 2002.
RESPONSE of the government of the Czech Republic to the report of the European Committee for the Prevention of Torture and Inhuman for Degrading Treatment or Punishment (CPT). Strasbourg, 2002.

UNITED KINGDOM. House of Commons report from the Education \& Skills Select Committee. London: Forum on Prisoner Education, 2005.

ZIPPERER, M. Tackling tuberculosis in Latvia. PLoS Med, v. 2, n. 5, e1. 22, 2005.

HUGO RANGEL, mestre em ciências da educação pela Universidade de McGill, mestre em sociologia e doutor em ciências da educação pela Universidade de Montreal, é membro do Sistema Nacional de Investigadores do Consejo Nacional de Ciencia e Tecnologia (SNI/CONACYT), no Canadá, e docentepesquisador (pós-doutorado) na Université du Québec à Montréal, no Departamento de Política e Educação. Dirigiu vários projetos de pesquisa sobre a educação de adultos no meio carcerário, com a Internacional Watch on Education in Prison (IWEP), notadamente o projeto "Educação prisional, estado da arte na Europa", em colaboração com a Comissão Européia e o Instituto da Organização das Nações Unidas para a Educação, a Ciência e a Cultura (UNESCO) para a Educação de Hamburgo. Suas pesquisas dedicam-se também às identidades coletivas, à cidadania, à democracia, às políticas educativas e à filosofia política. Publicou: International trends in education in prison (ICAE, Conseil International pour l'Education des Adultes, 2003), e, recentemente, "Le principe de liberté académique dans l'ère du conservatisme et la globalisation" (McGill Journal of Education, 2006). E-mail: hugo.rangel@elf.mcgill.ca 


\section{Resumos/Abstracts/Resumens}

Hugo Rangel

Estratégias sociais e educação prisional na Europa: visão de conjunto e reflexões

Este texto tem por origem uma pesquisa e constitui um sobrevôo do estado da arte sobre a educação prisional na Europa, tendo por objetivo identificar os problemas de ordem organizacional, metodológica e social que a limitam ou a determinam. Comporta uma reflexão, em vários planos e aspectos, sobre as atividades educativas desenvolvidas nas prisões, assim como sobre o papel e a significação dessas atividades educativas para as sociedades, seus sistemas judiciários e penitenciários. Procura estabelecer uma relação entre as estratégias sociais e a educação desenvolvida nas prisões européias.

Palavras-chave: educação prisional; educação ao longo da vida; educação para o trabalho; educação e cidadania

Social strategies and prison education in Europe: an overview

\section{and reflection}

This text is based on the results of a research project and constitutes an overview of the state of the art in prison education in Europe with the aim of identifying organizational, methodological and social problems which limit or determine it. It contains a reflection, on various levels and aspects, on the educational activities developed in prisons, as well as on the role and meaning of these educational activities for societies, their judiciary and penitentiary systems. It seeks to establish a relationship between social strategies and that education developed in European prisons.

Key words: prison education; lifelong education; education for work; education and citizenship

Estrategias sociales y educación en las prisiones en Europa: visión de conjunto y reflexión

Este trabajo tiene por origen una pesquisa y constituye un sobrevuelo del estado del arte sobre la educación en las prisiones en Europa, teniendo por objetivo identificar los problemas de orden organizacional, metodológica y social que la limitan o la determinan. Comporta una reflexión, en varios planos y aspectos, sobre las actividades educativas desenvueltas en las prisiones, así como sobre el papel y la significación de esas actividades educativas para las sociedades, sus sistemas judiciales y penitenciarios. Procura establecer una relación entre las estrategias sociales y la educación desenvuelta en las prisiones europeas. Palabras claves: educación de jóvenes y adultos; derecho a la educación; alfabetización; educación prisional; educación a lo largo de la vida; educación para el trabajo; educación y ciudadanía 